\title{
Design of the EO-1 Pulsed Plasma Thruster Attitude Control Experiment
}

\author{
Charles Zakrzwski \\ Guidance. Navigation, and Control Center \\ NASA-Goddard Space Flight Center \\ Greenbelt, MD 20771 \\ Paul Sanneman and Teresa Hunt \\ Swales Aerospace \\ Beltsville, MD 20705 \\ Kathie Blackman \\ the Hammers Company \\ Greenbelt, MD 20770
}

\begin{abstract}
$\underline{\text { Abstract }}$
The Pulsed Plasma Thruster (PPT) Experiment on the Earth Observing 1 (EO-1) spacecraft has been designed to demonstrate the capability of a new generation PPT to perform spacecraft attitude control. The PPT is a small, self-contained pulsed electromagnetic propulsion system capable of delivering high specific impulse (900-1200 s), very small impulse bits $(10-1000 \mu \mathrm{N}-\mathrm{s})$ at low average power $(<1$ to $100 \mathrm{~W})$. EO-1 has a single PPT that can produce torque in either the positive or negative pitch direction. For the PPT in-flight experiment, the pitch reaction wheel will be replaced by the PPT during nominal EO-1 nadir pointing. A PPT specific proportional-integral-derivative (PID) control algorithm was developed for the experiment. High fidelity simulations of the spacecraft attitude control capability using the PPT were conducted. The simulations, which showed PPT control performance within acceptable mission limits, will be used as the benchmark for on-orbit performance. The flight validation will demonstrate the ability of the PPT to provide precision pointing resolution, response and stability as an attitude control actuator.
\end{abstract}

\section{Introduction}

A Pulsed Plasma Thruster (PPT) is being flown as a technology demonstration experiment on Goddard Space Flight Center's (GSFC) Earth Observing 1 (EO1) mission. PPTs can offer significant mass saving benefits to spacecraft by replacing the combinations of

Copyright (o) 2001 hy the American Institute of Aeronautics and Astronautics. Inc. No copyright is asserted in the linited States under Title 17. U.S. Code. The II.S Cimemment has at royalty-free license to exercise all rights under the copyright herein clamed for Governmental Purposes All other rights are reserved by the copyright ouner reaction wheels, torque rods, and chemical thrusters. ${ }^{1.2}$ PPTs have the advantage of being simple to integrate to spacecraft because of the limited mechanical mounting hardware and electrical requirements. PPTs also eliminate safety and component layout complexities associated with fluid propellant propulsion systems.

The EO-1 PPT is the first flight PPT developed in over 10 years and incorporates significant improvements over the previous generation of PPTs. The EO-1 PPT flight experiment will demonstrate the ability of this new generation of PPT to provide precision attitude control and confirm benign interaction with other spacecraft subsystems and instruments. This experiment is the collaborative effort of NASA GFSC, NASA Glenn Research Center (GRC), General Dynamics Ordnance and Tactical Systems (formerly Primex Aerospace Corporation), and Swales Aerospace in partnership with the Hammers Company. This paper will describe the implementation of the PPT as an attitude control actuator.

\section{Background}

In 1994. NASA Glenn Research Center and its industry partner Primex Aerospace Company initiated the development of a new generation of PPTs to meet the forecasted demands of the growing small satellite community. The Air Force's Mighty Sat II program and NASA's EO-1 New Millennium Mission offered the first potential flight demonstrations for this technology. Mighty Sat II required primary delta-V propulsion and EO- 1 offered the potential for attitude control propulsion. GRC teamed with GSFC to propose and implement the PPT flight experiment on EO-1. The initial proposal consisted of flying several PPT units on EO- 1 to provide three-axis control of the spacecraft. Since the primary mission objective of 
EO-1 is to demonstrate advanced earth science instrument technology, spacecraft bus technology validation experiments were allocated lower funding and assessed higher risk factors. This led to a reduction in scope of the proposed PPT flight demonstration.

The minimum objective, flight validating attitude control utilizing advanced PPT technology, was achievable by flying a single PPT unit. The PPT would replace the function of a single axis momentum wheel for a limited time during the mission. The decision to control the pitch axis was based on the ease of integrating the PPT hardware on the spacecraft bus.

To limit the cost of the EO-1 PPT experiment, changes to the existing advanced PPT design, changes to the heritage flight software and control algorithms, and the complexity of the spacecraft electronics hardware needed to interface with the PPT were kept to a minimum. This approach significantly impacted a number of design trade studies. Perhaps the most significant trade decision was the choice between operating the PPT at a fixed power level and varying the firing frequency or fixing the firing frequency and varying the power level. The PPT firing frequency was fixed at $1 \mathrm{~Hz}$ by the existing attitude control system (ACS) software implementation.

Another effort to reduce development and qualification cost was to maintain a common size for the main discharge capacitor between the proposed EO-1 and Mighty Sat II PPTs. Although the Mighty Sat II PPT program was eventually terminated because of programmatic reasons, its requirements determined the size of the main energy storage capacitor for both proposals. Initially, the microfarad size of the main capacitor was believed to be excessive for EO-1.
However, an increase in the spacecraft power requirements led to a larger solar array and the addition of the Hyperion instrument led to a further increase in payliad mass. As a result of these changes. the larger capacitor size was needed to provide sufficient torque authority.

\section{$\underline{\text { EO-1 Mission }}$}

The EO- 1 mission is managed by Goddard Space Flight Center. It is the first Earth Observing mission for the NASA New Millennium Program (NMP) ${ }^{3}$. The purpose of the mission is to validate revolutionary technologies contributing to the reduction in cost and increase in capabilities for future land imaging missions. The spacecraft carries three advanced land imaging instruments, the Advanced Land Imager (ALI), the Atmospheric Corrector, and the Hyperion (Hyperspectral Imager). The spacecraft also carries seven spacecraft bus technologies: the Wideband Advanced Recorder \& Processor (WARP), a deployable light-weight flexible solar array, an advanced $\mathrm{X}$-band phased array, autonomous formation flying software, a fiber optic data bus, a carbon-carbon radiator, and the $\mathrm{PPT}$.

EO-1 was launched on November 21, 2000 into a 705 $\mathrm{km}$ circular, sun-synchronous orbit at a 98.7-degree inclination. It flies within one minute of the Landsat 7 spacecraft in order to collect identical images for comparison and validation. As of May 11,2001, a full series of calibration and performance scenes has been collected for all three instruments. Preliminary results of the analyses of the scenes indicate that all three instruments are performing as specified. All spacecraft bus technologies, excluding the PPT, have also been demonstrated successfully.

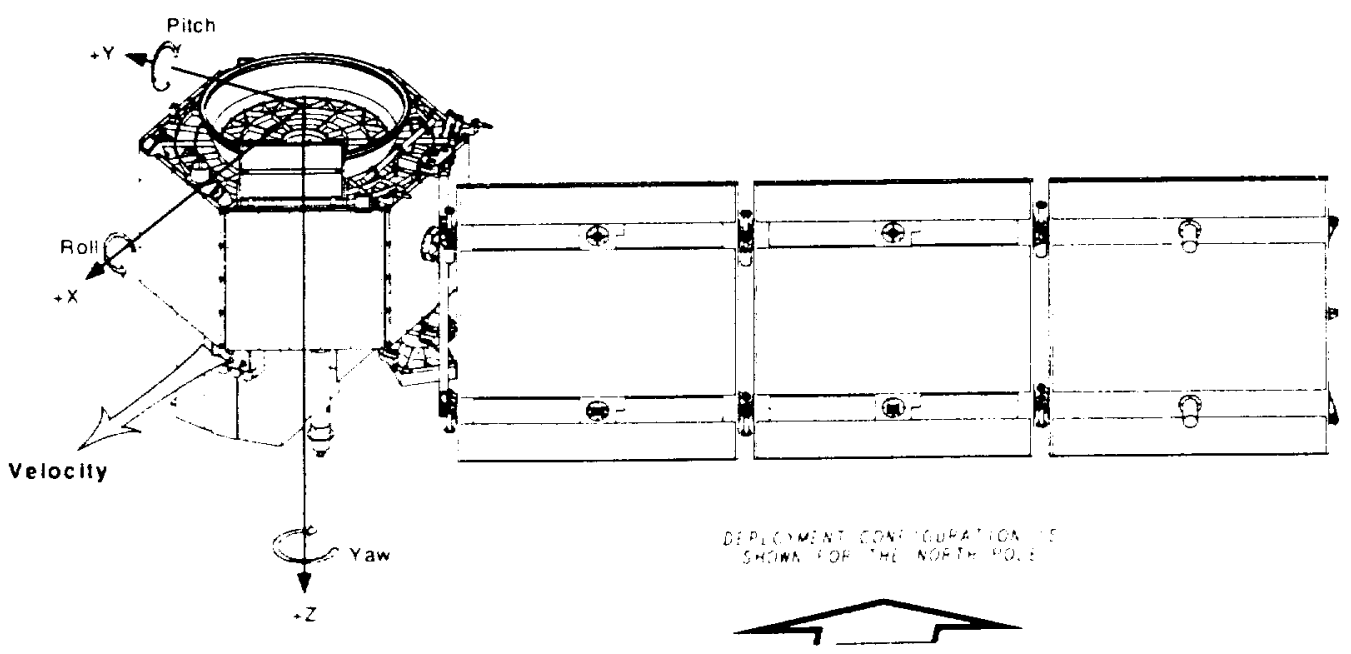

Fioure 1: FO-1 Snarecraft Axic Definition

2

American Institute of Aeronautics and Astronautics 


\section{EO-1 Spacecraft Bus}

EO-1 is a three-axis stabilized, nadir pointing. $565 \mathrm{~kg}$ spacecraft with a single rotating solar array. Figure 1 shows the spacecraft in the deployed configuration and identifies the spacecraft control axes. The primary features of all major subsystems are given in Table 1.

Table 1: EO-1 Spacecraft Characteristics

\begin{tabular}{|c|c|}
\hline $\begin{array}{l}\text { Attitude Control and } \\
\quad \text { Navigation } \\
\text { - 3-Axis stabilized } \\
-0.03 \text { deg. Pointing } \\
\text { accuracy in all axes } \\
\text { - } 5 \text { arc seconds jitter } \\
\text { - GPS receiver for onboard } \\
\text { navigation } \\
\text { - Autonomous formation } \\
\text { flying capability } \\
\text { - Independent safe hold } \\
\text { processor }\end{array}$ & $\begin{array}{l}\text { Communications and } \\
\text { Data Storage } \\
\text { - Science data transmitted over } \\
\text { X-band at } 105 \mathrm{Mb} / \mathrm{sec} \text {. with } \mathrm{S} \\
\text { band backup at } 2 \mathrm{Mb} / \mathrm{sec} \\
\text { - Housekeeping telemetry at } 1 \\
\mathrm{Mb} / \mathrm{sec} \text { or } 2 \mathrm{~Kb} / \mathrm{sec} \\
\text { - Command uplink } 2 \mathrm{~Kb} / \mathrm{sec} \\
\text { - } 40 \text { Gbits storage capability } \\
\text { with Wideband Advanced } \\
\text { Recorder Processors }\end{array}$ \\
\hline $\begin{array}{l}\text { Power } \\
\text { - } 3 \text { panel, silicon cells, } \\
\text { single axis articulating } \\
\text { - } 600 \mathrm{~W} \text { EOL ( } 300 \mathrm{~W} \text { orbit } \\
\text { average) } \\
\text { - } 50 \mathrm{~A} \text {-hr super Ni-Cd } \\
\text { battery } \\
-28+1-7 \text { V DC }\end{array}$ & $\begin{array}{l}\text { Propulsion } \\
\text { - Four } 1 \mathrm{~N} \text { Hydrazine thrusters } \\
\text { canted } 15 \text { degrees for } 3 \text { axis } \\
\text { control } \\
\text { - } 22.3 \mathrm{~kg} \text { propellant in } \\
\text { elastomeric diaphragm tank } \\
\text { - Provides delta- } V \text { for } \\
\text { insertion error correction, orbit } \\
\text { maintenance. formation flying, } \\
\text { and de-orbit }\end{array}$ \\
\hline $\begin{array}{l}\text { Control and Data } \\
\text { Processing } \\
-12 \mathrm{MHz} \text { Mongoose } 5 \\
\text { Processor } \\
-1.8 \text { Gbits of telemetry and } \\
\text { command storage } \\
-1773 \text { Fiber Optics Data } \\
\text { Bus }\end{array}$ & $\begin{array}{l}\text { Thermal } \\
\text {-Cold-bias, } 0-40 \text { degree } C \\
\text { - Thermostatically controlled. } \\
\text { redundant heaters }\end{array}$ \\
\hline
\end{tabular}

\section{Attitude Control System}

The Attitude Control Subsystem (ACS) performs the pointing. or orientation, of the spacecraft body and subsystems during all phases of on-orbit operation. Subsystems such as power, thermal, and communications as well as the science instruments require attitude control. A suite of attitude sensors, actuators, and control laws perform the attitude control functions. The PPT functions as an attitude control actuator.
The top-level architecture and major components of the $\mathrm{ACS}$ are shown in Figure 2. All the attitude control functions are performed within the Attitude Control and Data Systems (ACDS) electronic box. Within the ACDS are four Attitude Control Electronics (ACE) circuit cards and four Command and Data Handling ( $C \& D H)$ circuit cards. The ACE circuit cards include the ACE Input/Output, ACE Remote Services Node (RSN), Propulsion System Input/Output, and ACE Low Voltage Power Converter. The relevant C\&DH circuit cards are the Mongoose 5 main spacecraft processor and the Housekeeping Remote Services Node. A local power and signal back-plane connect all of the ACE boards to each other. The ACE RSN is connected to the Mongoose 5 and other components by the 1773 fiber optic bus.

The primary attitude control software resides in the Mongoose 5 main spacecraft computer. The Safe Hold Mode software and electronics interfaces to most of the ACS components reside in the ACE. The key features of the sensor and actuator components are given in Table 2. The spacecraft mode determines the complement of sensors and actuators used for attitude control. The Mission Idle mode, which is the only mode that uses the PPT, will be discussed below.

Table 2: ACS Sensors and Actuators

\begin{tabular}{|c|c|}
\hline Component & Description \\
\hline $\begin{array}{l}\text { Reaction Wheel Assembly } \\
\text { (RWA) }\end{array}$ & $\begin{array}{l}3 \text { Wheels, one per axis } \\
+/-4 \mathrm{~N} \mathrm{~s} \text { at } 5100 \mathrm{RPM} \text {, } \\
+/-0.025 \mathrm{~N} \mathrm{~m} \max \text { torque }\end{array}$ \\
\hline $\begin{array}{l}\text { Magnetic Torquer Bars } \\
\text { (MTB) }\end{array}$ & $\begin{array}{l}3 \text { Bars, one per axis } \\
+/-60 \mathrm{Am}^{2} \text { linear dipole } \\
\text { moment }\end{array}$ \\
\hline $\begin{array}{l}\text { Three Axis Magnetometer } \\
\text { (TAM) }\end{array}$ & $\begin{array}{l}+/-1.0 \text { Gauss on each axis } \\
0.05 \text { micro Tesla resolution }\end{array}$ \\
\hline $\begin{array}{l}\text { Inertial Reference Unit } \\
\text { (IRU) }\end{array}$ & $\begin{array}{l}+/-10 \mathrm{deg} / \mathrm{sec} \max \text { rate } \\
0.05 \text { arc-seconds resolution }\end{array}$ \\
\hline $\begin{array}{l}\text { Autonomous Star Tracker } \\
\text { (AST) }\end{array}$ & $\begin{array}{l}8 \times 8 \text { deg. FOV } \\
\text { Attitude output } 5.5,25 \text { arc- } \\
\text { sec. } 1 \text {-sigma }\end{array}$ \\
\hline GPS Receiver & $\begin{array}{l}+/-150 \mathrm{~m} \text { position } \\
+/-0.55 \mathrm{~m} / \mathrm{s} \text { velocity }\end{array}$ \\
\hline $\begin{array}{l}\text { Coarse Sun Sensor } \\
\text { (CSS) }\end{array}$ & $\begin{array}{l}4 \text { sensors } \\
600 \quad \text { micro-amps } \\
\text { output current }\end{array}$ \\
\hline Pulsed Plasma Thruster & $\begin{array}{l}90-860 \mathrm{~m} \text { Nsec impulse } \\
\text { bits. } 0.6 \mathrm{~m} \text { pitch moment } \\
\text { arm }\end{array}$ \\
\hline
\end{tabular}




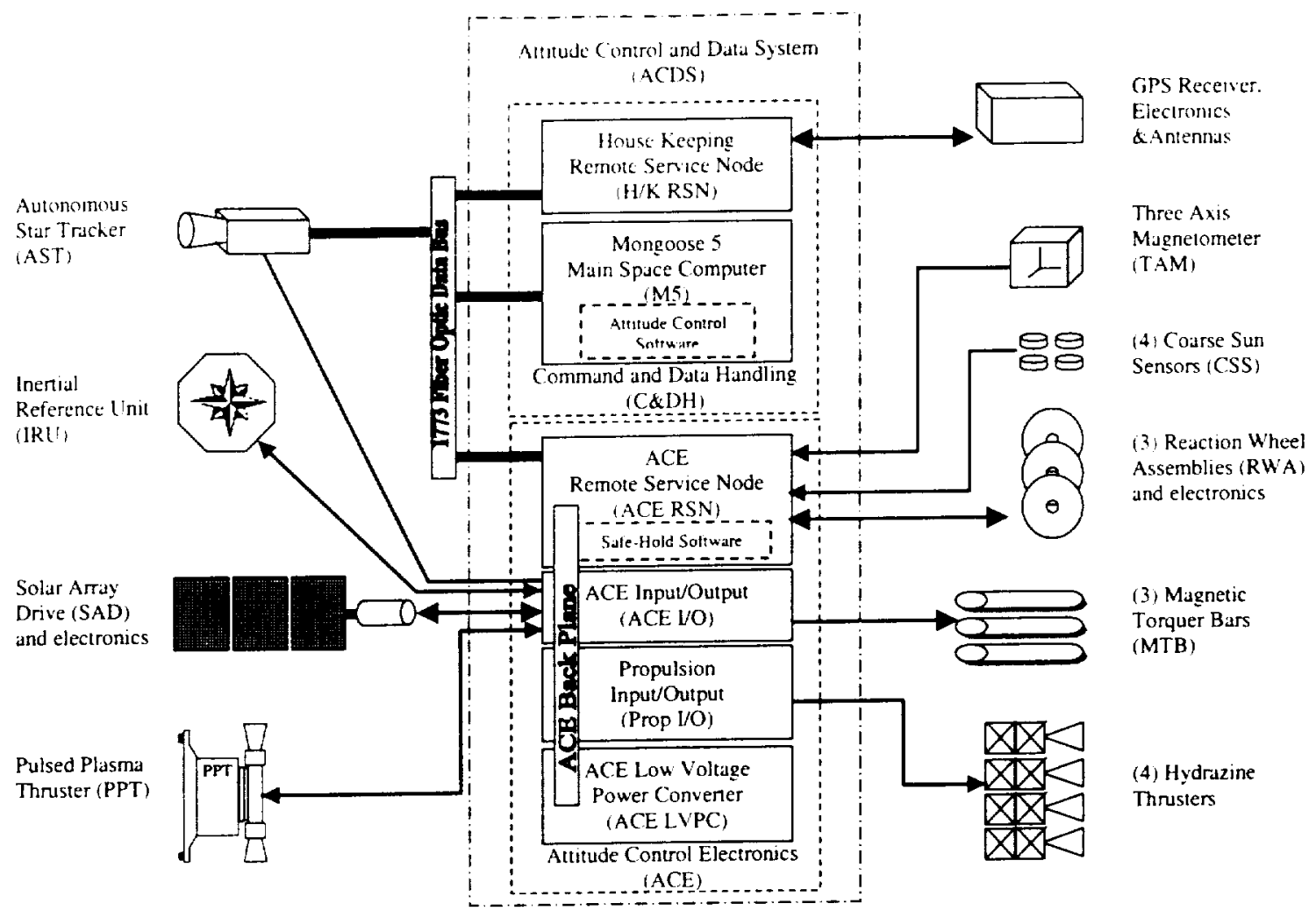

Figure 2: Controller for PPT Operation

PPT Description

\section{Principle of Operation}

The operation of the PPT is inherently simple. Referring to Figure 3, the main capacitor is initially charged to the desired level and then discharged across the face of a Teflon fuel bar. Two fuel bars are located between separate and opposing electrode pairs to provide thrust in the positive and negative $Z$-axis directions (the PPT location with respect to the center of mass results in $+1-$ pitch torque). The discharge of the main capacitor occurs when the spark plug on the desired electrode pair is commanded to fire. A minute amount of charged particles is ablated into the electrode gap when the spark plug is fired. These charged particles provide a conductance path that initiates the main capacitor discharge across the gap. The main capacitor discharge ablates a small amount of Teflon. A small percentage of the Teflon is ionized to form plasma. A Lorentz force accelerates the plasma producing thrust. Charged particle to neutral collisions. and pressure forces from resistive heating. produce additional acceleration of the neutral charged ablated Teflon. The PPT flight unit is shown attached to the EO-1 spacecraft in Figure 4.

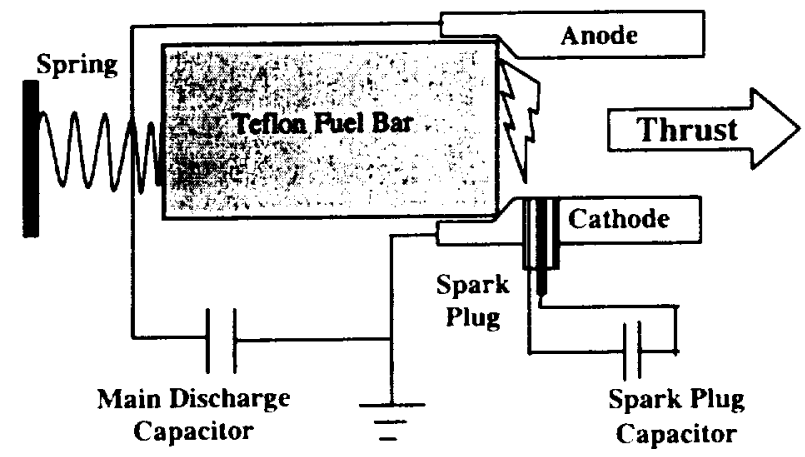

Figure 3: PPT Schematic

\section{EO-1 PPT Characteristics}

The detailed performance characteristics and development of the EO-1 PPT have been previously described ${ }^{4.5 .6}$. The important characteristics are given in Table 3. 


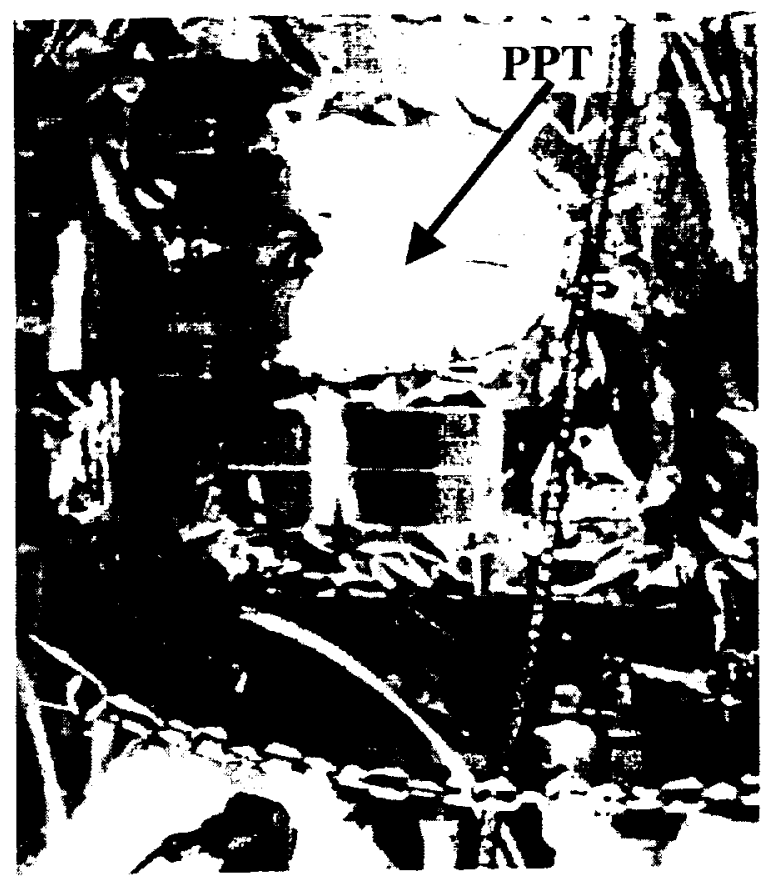

Figure 4: PPT on EO-1 Spacecraft

Table 3: PPT Characteristics

\begin{tabular}{|l|l|}
\hline Impulse Bit (per pulse) & $\begin{array}{l}90-860 \text { micro } \\
\text { Nsec }\end{array}$ \\
\hline Specific Impulse & $650-1400 \mathrm{sec}$ \\
\hline Pulse Frequency & $1 \mathrm{~Hz}$ \\
\hline Main Capacitor Energy & $8.5-56 \mathrm{~J}$ \\
\hline Overall Thrust/Power Efficiency & $8 \%$ \\
\hline Total Mass & $4.95 \mathrm{~kg}$ \\
\hline Fuel Mass & $0.07 \mathrm{~kg}$ per side \\
\hline Total Impulse (estimated) & $460 \mathrm{~N}-\mathrm{sec}$ \\
\hline Orbital Average Power (estimated) & $12.6 \mathrm{~W}$ \\
\hline
\end{tabular}

For EO-1, the firing rate was fixed at $1 \mathrm{~Hz}$. To modulate the thrust. the magnitude of the impulse bit is varied. The magnitude of the impulse bit is changed by varying the charge time of the main capacitor. The length of time the main capacitor charges directly affects the amount of energy in the capacitor and. consequently. the amount of thrust produced during the discharge. The relationship between the impulse bit per firing as a function of capacitor charge time is shown for each firing side of the PPT in Figure 5.

The differences in performance between the two sides are most likely a result of slightly different spark plug characteristics and electrode properties. The most significant source of shot-10-shot variability comes from the PPT temperature change. The maximum and minimum impulse bits ohtained at the maximum and minimum PPT operating temperatures are plotted in Figure 5.

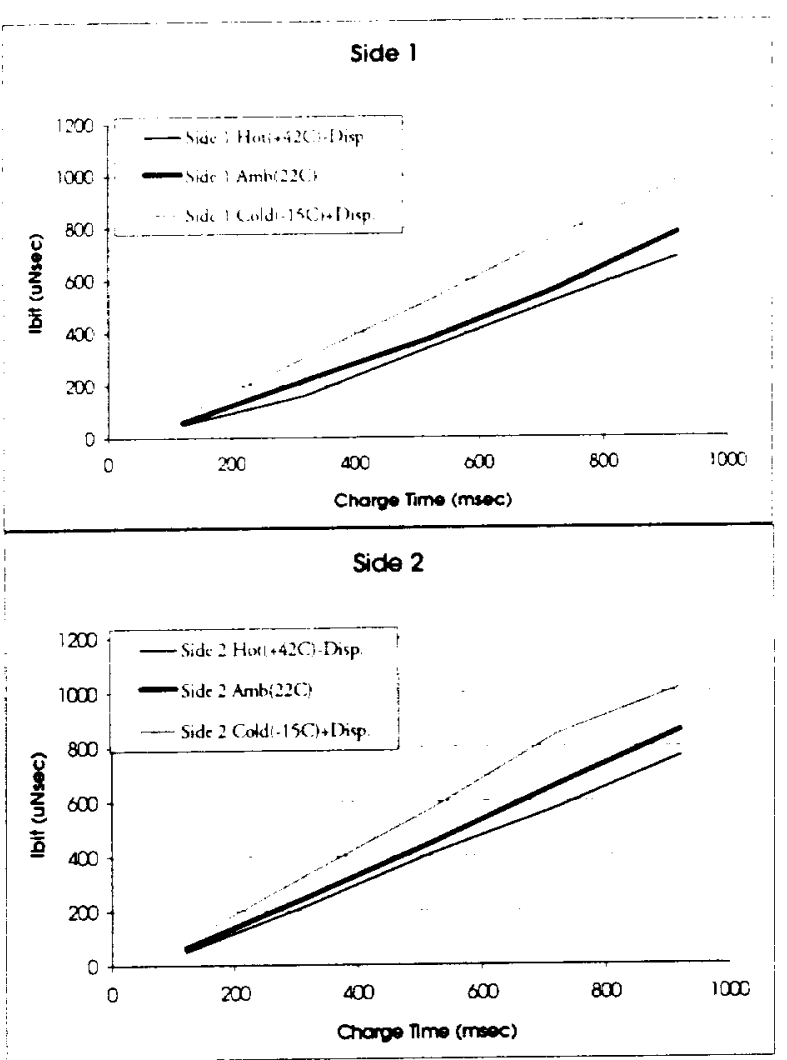

Figure 5: PPT Impulse Bit versus Charge Time

The variability of impulse bit due to temperature changes is attributed to the thermal sensitivity of the charging circuit. This shot-to-shot variability can easily be narrowed for future PPT development. This temperature dependant variation in impulse bit was acceptable for the EO-1 flight demonstration because of the characteristics of the closed-loop control laws and the predicted thermal environment of the PPT during operation.

\section{PPT to Spacecraft Interface}

The mechanical and electrical interfaces between the PPT and the spacecraft bus are relatively simple. The mechanical mounting and orientation of the PPT on the spacecraft is shown in Figure 6. Two harnesses, one for power and one for command and telemetry, are used for the electrical interface. The power harness connects the PPT to a power subsystem output module providing 28 $+/-7 \mathrm{~V}$ from the unregulated spacecraft power bus The command and telemetry harness connects the PPT to the ACE Input/Output card. The services provided are: 
PPT Commands:

- Charge Main Capacitor (0-5V logic)

- Fire Spark Plug \# I (0-5Vlogic)

- Fire Spark Plug \# $2(0-5 \mathrm{~V}$ logic $)$

PPT Telemetry:

- Main Capacitor Voltage

- Spark Plug \#1 Capacitor Voltage

- Spark Plug \#2 Capacitor Voltage

- Main Capacitor Temperature

- PPT Transformer Temperature

- Fuel Bar \#1 reading (length of bar)

- Fuel Bar \#2 reading (length of bar)

The PPT commands are sequenced by the attitude control subsystem. As mentioned above, the attitude control subsystem software operates at a $1 \mathrm{~Hz}$ cycle rate. The ACE operates at a faster $25 \mathrm{~Hz}$ rate. The ACE rate allows PPT commands to be quantized in 40 msec increments within each one second attitude control software cycle.

Figure 7 shows an example of a command sequence that fires PPT side \#1 twice. The main capacitor is charged for the length of time its command signal is switched from logic zero to logic high. The charge time length must be between 120 and $920 \mathrm{msec}$. The minimum charge length is determined by the minimum energy at which the PPT will reliably discharge. The maximum time is set by the need to charge the main capacitor, fire the appropriate spark plug, and discharge the main capacitor to $0 \mathrm{~V}$ within the $1 \mathrm{~Hz}$. Cycle. Since $80 \mathrm{msec}$ are required to fire a spark plug and discharge the main capacitor. the maximum allowable time for main capacitor charging is limited to $920 \mathrm{msec}$.

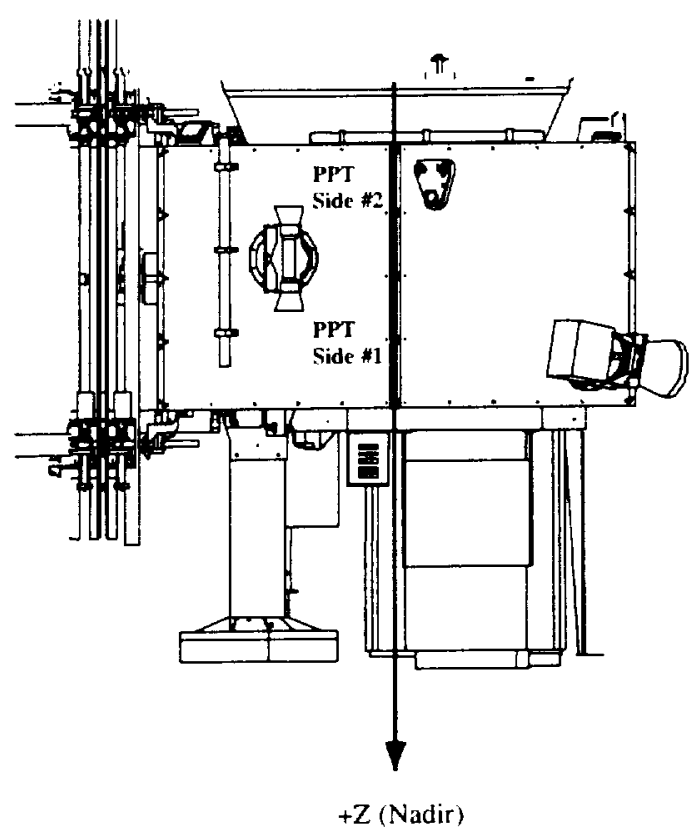

Figure 6: PPT Orientation on Spacecraft

A spark plug command signal will discharge the selected spark plug when the signal switches from low to high. The spark plug command for side 1 is kept high during main capacitor charging until the $\mathrm{ACE}$ cycle just prior to discharge. It is then switched low so that it can switch back to high and fire the PPT in the next ACE cycle. The PPT fires within $50 \mu \mathrm{sec}$ of the command transition. The spark plug command for the side that is not to be fired, in this case spark plug \#2. will receive the command sequence shown in the lower trace. This sequence was implemented to add insurance to the operational reliability of the PPT. The timing constraints for the both spark plug commands are given in the figure.

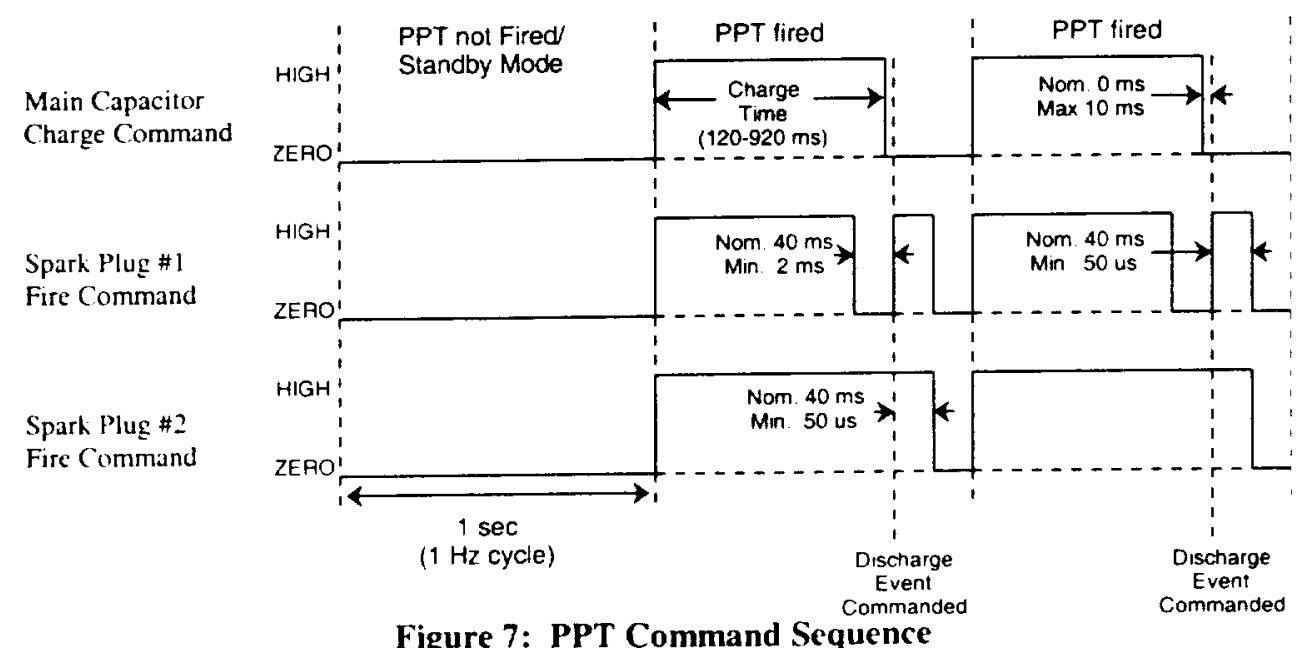

6

American Institute of Aeronautics and Astronautics 
Because of the sequence. the spark plug that was not commanded to fire in the current $1 \mathrm{~Hz}$ control cycle will discharge or "fire" at the beginning of the next control cycle. This is due to the presence of charge on the unfired spark plug capacitor as the spark plug command signals are brought from high to low at the beginning of each control cycle. Because the main capacitor is not charged at this point. no thrust is produced and neither the PPT nor the attitude control system is affected.

\section{Attitude Control Mode for PPT validation}

The various on-orbit mission modes of the EO-1 spacecraft are shown in Figure 8 . The PPT validation demonstration will occur in Mission Idle Mode. Science Imaging Mode is not used on orbit, and science data observations are collected during Mission Idle Mode. In Mission Idle Mode, the spacecraft holds a constant attitude with respect to the Earth in the orbit reference frame. During orbit day, the solar array tracks the sun. Due to the use of a cable wrap mechanism to connect the solar array to the main body, the solar array must be rewound during orbit night. For this mode, the reaction wheels are the primary actuators for control of attitude errors and rates. The magnetic

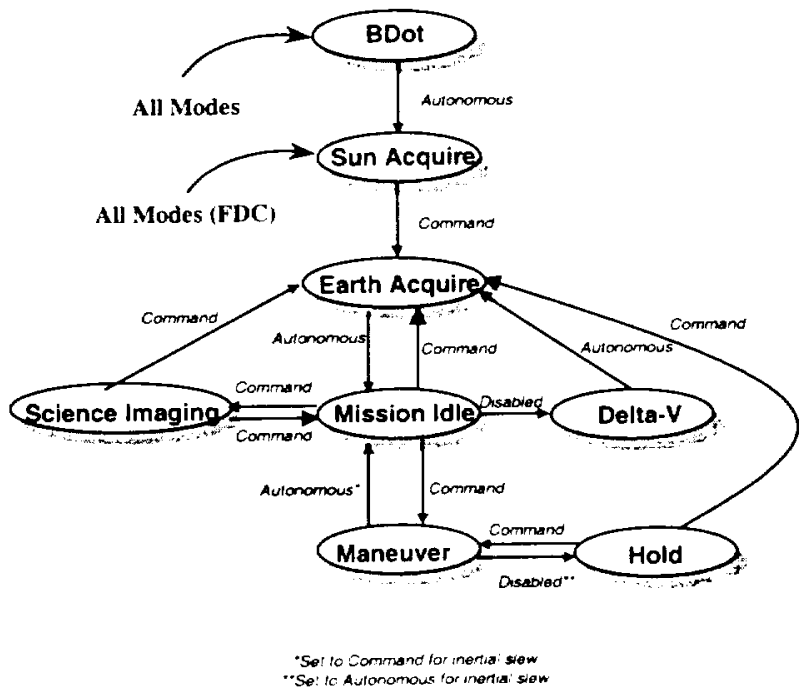

Figure 8: EO-1 ACS Control Modes torquer bars are used to provide constant momentum management. keeping the reaction wheel speeds within the desired limits. The inertial reference unit (IRU) and star tracker are used for attitude determination. and the GPS receiver is used for orbital navigation vectors and time.

The time line for science imaging in the nominal actuator configuration using three reaction wheels is shown in Figure 9. To minimize disturbances due to reaction wheel imbalances, the wheels are biased to a speed that reduces jitter (shown here as 1000 RPM). In addition to biasing the wheels, the solar array is parked at a fixed angle just prior to imaging in order to eliminate any jitter induced by the solar array drive.

To improve image acquisition and validation, the option of slewing the spacecraft such that the $+Z$ axis is offnadir was added. The PPT torque capability was determined and analyzed prior to the mission operations change for off-nadir scenes on a regular basis. Since the torque required for slew maneuvers exceeds the torque capability of the PPT, the off-nadir slew option will not be available during the PPT validation phase of the mission.

\section{Mission Idle Controller using PPT}

\section{System Description}

The PPT-based control algorithm and analysis models for Mission Idle Mode are described in block diagram form in Figure 10. This architecture was used for system analysis and the appropriate portions were implemented in flight software. Three axis attitude measurements ( $y_{\text {inu }}$ ) from the IRU's gyros are differenced with the commanded attitude state $\left(y_{c}(t)\right)$ to produce a position error vector $(e(t))$. A proportionalintegral-derivative (PID) controller is used to produce computed torque commands $\left(u_{c}(k)\right)$. An anti-aliasing filter is used in series with the PID controller to attenuate any structural flexibility and improve system stability. The filter is a $0.1 \mathrm{~Hz}$ discrete second order filter, and it returns a vector of discrete roll. pitch, and yaw commands $(u(k))$.

The roll and yaw commands $([u(k)] x$ and $[u(k)] y)$ are

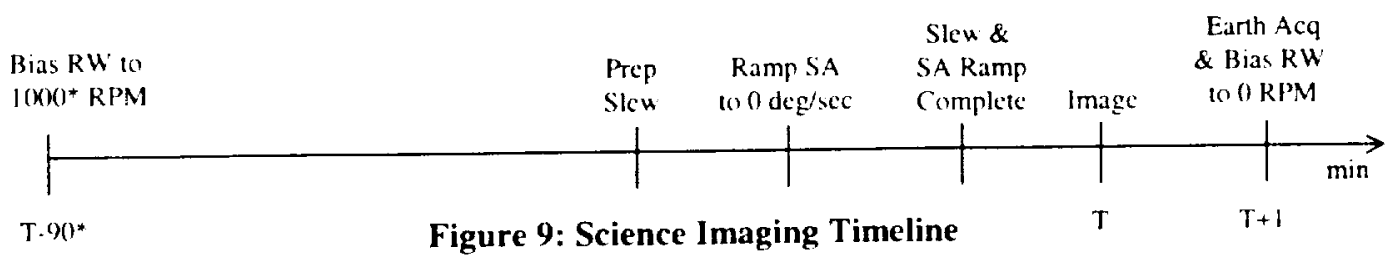

7

American Institute of Aeronautics and Astronautics 


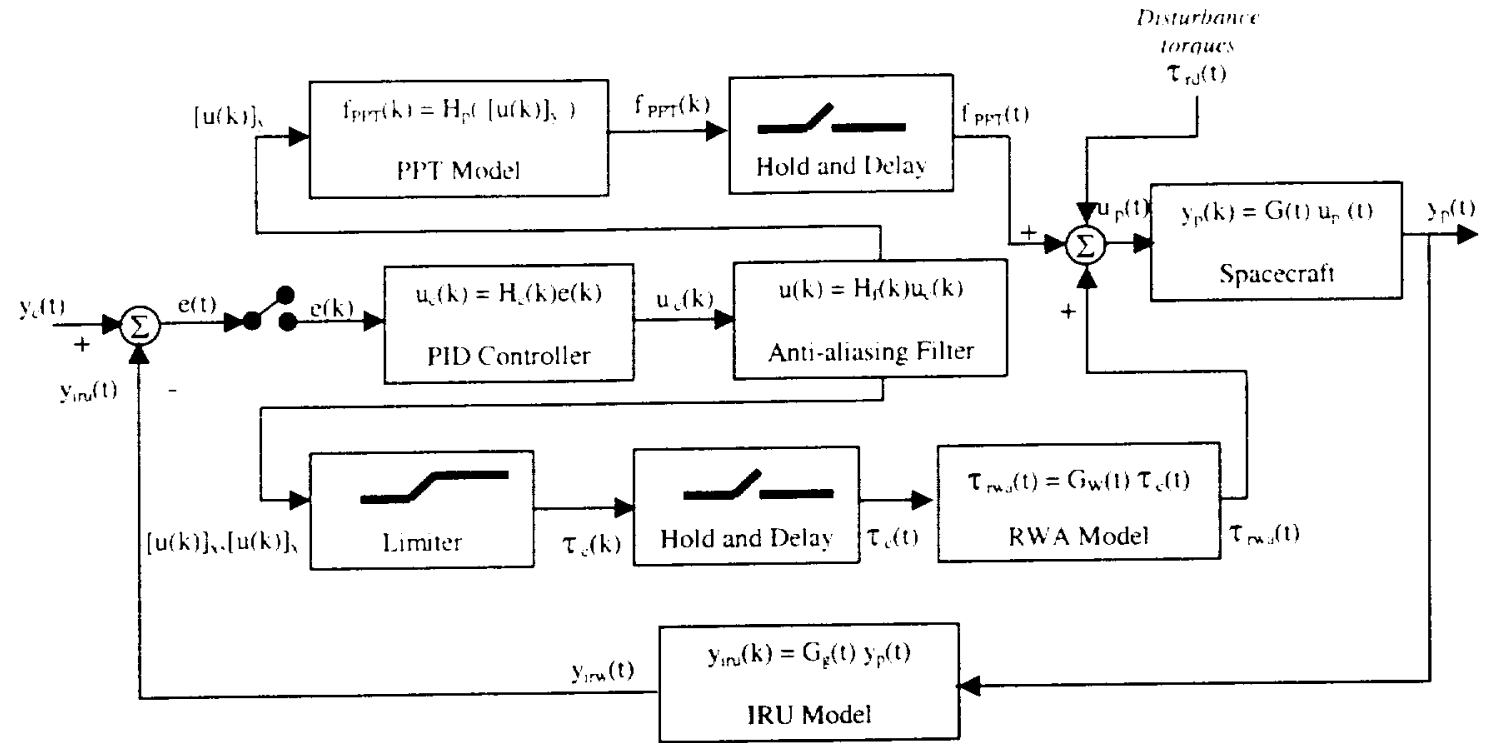

Figure 10: Controller for PPT Experiment

processed the same for both the PPT control mode and the all wheel control mode. Roll and yaw commands are amplitude limited to $0.025 \mathrm{Nm}\left(t_{c}(k)\right)$, converted to an analog signal and then sent to the reaction wheels following a 0.5 second computational delay. For simulations, the command torques sent to the reaction wheels $\left(t_{c}(k)\right)$ are input to a reaction wheel model which includes wheel friction and returns a reaction wheel torque $\left(t_{\text {rva }}(t)\right)$. The pitch command $(u(k)]_{y}$ is input to a PPT model which includes processor logic to determine PPT on-times and a PPT model that outputs the PPT force $f_{P P T}(k)$ for simulations. Unlike discrete roll and yaw commands, which are sampled through a zero order hold process, PPT induced forces act on the spacecraft only for the duration specified by each ontime request issued at each discrete event (although delayed by 0.5 seconds due to processor time lag). For simulation purposes, a combination of reaction wheel torques, PPT forces, and disturbance torques $\left(u_{p}(t)\right)$ is fed to the spacecraft model to yield a resulting spacecraft attitude state $\left(y_{p}(t)\right)$.

\section{PID Controller}

The PID controller bandwidth is set to $0.016 \mathrm{~Hz}$ to ensure stability through adequate separation between the controller and both the flexural spacecraft modes and the sample-and-hold process. The discrete Laplace $z$-transform of this control block can be written as:

$$
\frac{\mathrm{u}_{\mathrm{c}}^{\prime}(\mathrm{z})}{\mathrm{e}^{\prime}(\mathrm{z})}=\left[\mathrm{K}_{\mathrm{p}}^{\prime}+\mathrm{K}_{\mathrm{i}}^{\prime}\left(\frac{1}{\mathrm{z}-1}\right)+\mathrm{K}_{\mathrm{d}}^{\prime}\left(\frac{\mathrm{z}-1}{\mathrm{z}}\right)\right]
$$

where $K_{r}^{\prime}$. $K_{1}^{\prime}$, and $K_{d}^{\prime}$ are respectively, the proportional, integral, and derivative control gains for axis $(j)$. The control gains for both the PPT control mode and the all reaction wheel control mode are given in Table 4 . The only difference between the two actuator sets is the pitch integral control gain value. For PPT operation, this $\mathrm{K}_{\mathrm{i}}$ gain is smaller in order to avoid PPT limit cycling during solar array disturbances.

\begin{tabular}{|l|l|l|l|l|}
\hline Actuators & Axis & $\mathbf{K}^{\mathbf{j}}{ }_{\mathrm{p}}$ & $\mathbf{K}_{\mathbf{i}}^{\mathbf{j}}$ & $\mathbf{K}_{\mathrm{d}}^{\mathbf{j}}$ \\
\hline & \multicolumn{3}{|c|}{} \\
\hline \multirow{3}{*}{$\begin{array}{l}\text { PPT, Roll \& } \\
\text { Yaw RWA }\end{array}$} & Roll & $\mathbf{1 . 3 9 1 9}$ & $\mathbf{. 0 3 0 6 3 4}$ & $\mathbf{4 7 . 4 4 1}$ \\
\cline { 2 - 5 } & Pitch & $\mathbf{0 . 6 1 7 1 6}$ & $\mathbf{. 0 0 3 3 2 1}$ & $\mathbf{2 1 . 0 3 5}$ \\
\cline { 2 - 5 } & Yaw & $\mathbf{1 . 4 2 3 8}$ & $\mathbf{. 0 3 1 3 3 6}$ & $\mathbf{4 8 . 5 2 8}$ \\
\hline & \multicolumn{3}{|c|}{} \\
\hline \multirow{3}{*}{$\begin{array}{l}\text { Roll, Pitch, } \\
\text { Yaw RWA }\end{array}$} & Roll & $\mathbf{1 . 3 9 1 9}$ & $\mathbf{. 0 3 0 6 3 4}$ & $\mathbf{4 7 . 4 4 1}$ \\
\cline { 2 - 5 } & Pitch & $\mathbf{0 . 6 1 7 1 6}$ & $\mathbf{. 0 1 3 2 8 4}$ & $\mathbf{2 1 . 0 3 5}$ \\
\cline { 2 - 5 } & Yaw & $\mathbf{1 . 4 2 3 8}$ & $\mathbf{. 0 3 1 3 3 6}$ & $\mathbf{4 8 . 5 2 8}$ \\
\hline
\end{tabular}

\section{Table 4: Science Mode Control Gains}

The discrete Laplace $z$-transform of the anti-aliasing filter is given by:

$$
\frac{u^{j}(z)}{u_{c}^{\prime}(z)}=\left(\frac{0.1453 z+0.1079}{z^{2}-1.158 z+0.4112}\right)
$$

This provides unity gain and a second order roll-off at $0.1 \mathrm{~Hz}$

\section{PPT Model}

The logic flow of the PPT Model block is illustrated in block form in Figure 11. The commanded pitch torque $\left\{u_{c}(k)\right\} y$ is converted to an ideal force level $\left(\mathrm{F}^{\mathrm{k}}{ }_{\text {ideal }}\right)$ by simply dividing the torque by the moment arm. The length of the PPT pitch momentum arm is approximately $0.6 \mathrm{~m}$. For this modeling effort. the impulse bit $\left(\mathrm{I}^{h}\right)$ delivered by the PPT and the main 


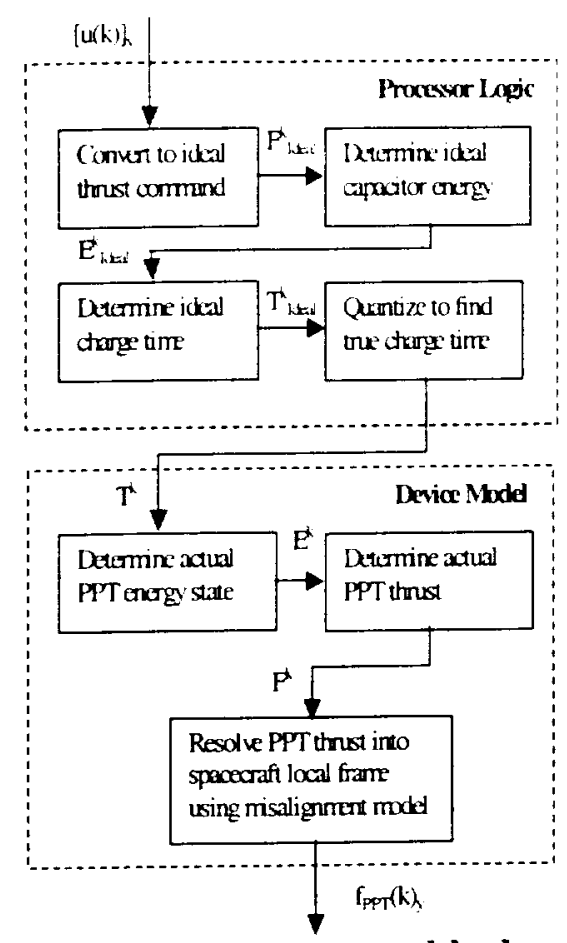

Figure 11: PPT Controller block

capacitor energy level ( $E^{k}$ ) are defined respectively as:

$$
\mathrm{I}^{\mathrm{k}}=\mathrm{F}^{\mathrm{k}} \mathrm{T}^{\mathrm{k}} \text {, and } \mathrm{E}^{\mathrm{k}}=\mathrm{PT}^{\mathrm{k}}
$$

where $\left(T^{k}\right)$ is the main capacitor charge time and $P$ is maximum instantaneous power $(65.2 \mathrm{~W})$. These two definitions can be used with the impulse bit versus charge time data given in Figure 5 to produce a second order polynomial curve fit describing the ideal energy level $\left(E^{k}{ }_{\text {ideal }}\right)$ as a function of ideal force level $\left(F^{k}\right.$ ideal $)$ :

$$
\mathrm{E}_{\text {ideal }}^{\mathrm{k}}=\mathrm{a}\left(\mathrm{F}_{\text {ideal }}^{\mathrm{k}}\right)^{2}+\mathrm{b}\left[\mathrm{F}_{\text {ideal }}^{\mathrm{k}}\right] \quad \mathrm{Eq} \text {.(5) }
$$

where $a=-1.9765 E-7 \mathrm{~J} / \mathrm{N}^{2}$ and $\mathrm{b}=78000 \mathrm{~J} / \mathrm{N}$. The actual flight software uses a weighted combination of this equation and a first order equation (i.e. $a=0$ ) to represent the actual PPT data over the entire range of charge times. The ideal capacitor energy is translated into an ideal charge time $\left(\mathrm{T}^{\mathrm{k}}\right.$ ideal $)$ by simply dividing by the maximum instantaneous power $(\mathrm{P})$. The ideal charge is then quantized to a true charge ( $\mathrm{T}^{\mathrm{k}}$ ) to be sent to the PPT side that produces the same sign of the pitch force as the ideal force $\left(\mathrm{F}^{\mathrm{k}}\right.$ ideal $)$. If $\left(\mathrm{T}^{\mathrm{k}}\right.$ ideal $)$ is less than $160 \mathrm{msec}$. ( $T^{k}$ ) is set to zero; if it is greater than $920 \mathrm{msec}$, it is set to $920 \mathrm{msec}$; for all other values, it is quantized to the nearest $40 \mathrm{msec}$ interval.

The Device Model used for simulations takes the true charge time and uses Equation 3 . as described below. to return a PPT energy state $\left(E^{k}\right)$. The energy state is converted to a thrust level $\left(F^{k}\right)$ and then resolved into a force applied to the spacecraft (f ppr $(k)$ ) by means of a misalignment model which uses small angle approximations.

\section{PPT Simulations}

A comprehensive nonlinear analysis was performed using a high-fidelity MATLAB-based simulation to evaluate the EO-1 attitude control performance with the PPT as the pitch axis actuator. The simulation included mass property variation, ephemeris models, and torques due to solar pressure, aerodynamic drag. gravity gradient, solar array movement, magnetic torquer bar momentum management, and momentum wheel friction. The first ten structural modes of the spacecraft were included as well as PPT pitch and roll misalignment errors of 3 degrees due to center of mass movement. For the simulations, the on-board controller described in Figure 8 was sampled at $1 \mathrm{~Hz}$ while the spacecraft model and disturbance torques were over sampled at $95 \mathrm{~Hz}$.

Shown in Figure 12 are the results of a standard EO-1 summer solstice orbit. Plots on the left side represent pointing errors from all three axes during the course of a complete orbit, derived from the difference between the desired attitude and integrated IRU measurements. The plots on the right side represent commands sent by the on-board processor to the actuators. The largest disturbance, and therefore the event requiring the largest output from the actuators, is the acceleration and deceleration of the solar array during orbit night rewind activities. These events begin at $\mathrm{t}=8.24$ and $\mathrm{t}=82.4$ minutes and last for 8 minutes. For the entire orbit. the worst-case roll, pitch, and yaw errors were found to be 52.1, 129.3, and 14.3 arcsec. Also, during the entire orbit the level of thrust required from the PPT never exceeded its maximum capability. The PPT was observed to induce flexural vibrations. These induced flexural vibrations were the dominant source of error in the roll axis during the imaging phase of the orbit $(t=$ 50 to $60 \mathrm{~min}$ ). However, both the roll and pitch pointing errors still did not exceed 5 arc-sec during that time frame. Using the total accumulated charge time of the PPT capacitor. the orbital average power consumption of the PPT was estimated to be $12.6 \mathrm{~W}$.

While the simulations show that the PPT has adequate capability to perform attitude control during science data collection for purposes of hardware validation. they also indicate areas of improvement for future PPT designs. Specifically, extending the impulse bit range at both the high and low ends would be useful. Reducing the minimum impulse bit may reduce the jitter and pointing errors during image taking. As suggested in Reference 3, this could easily be accomplished by 

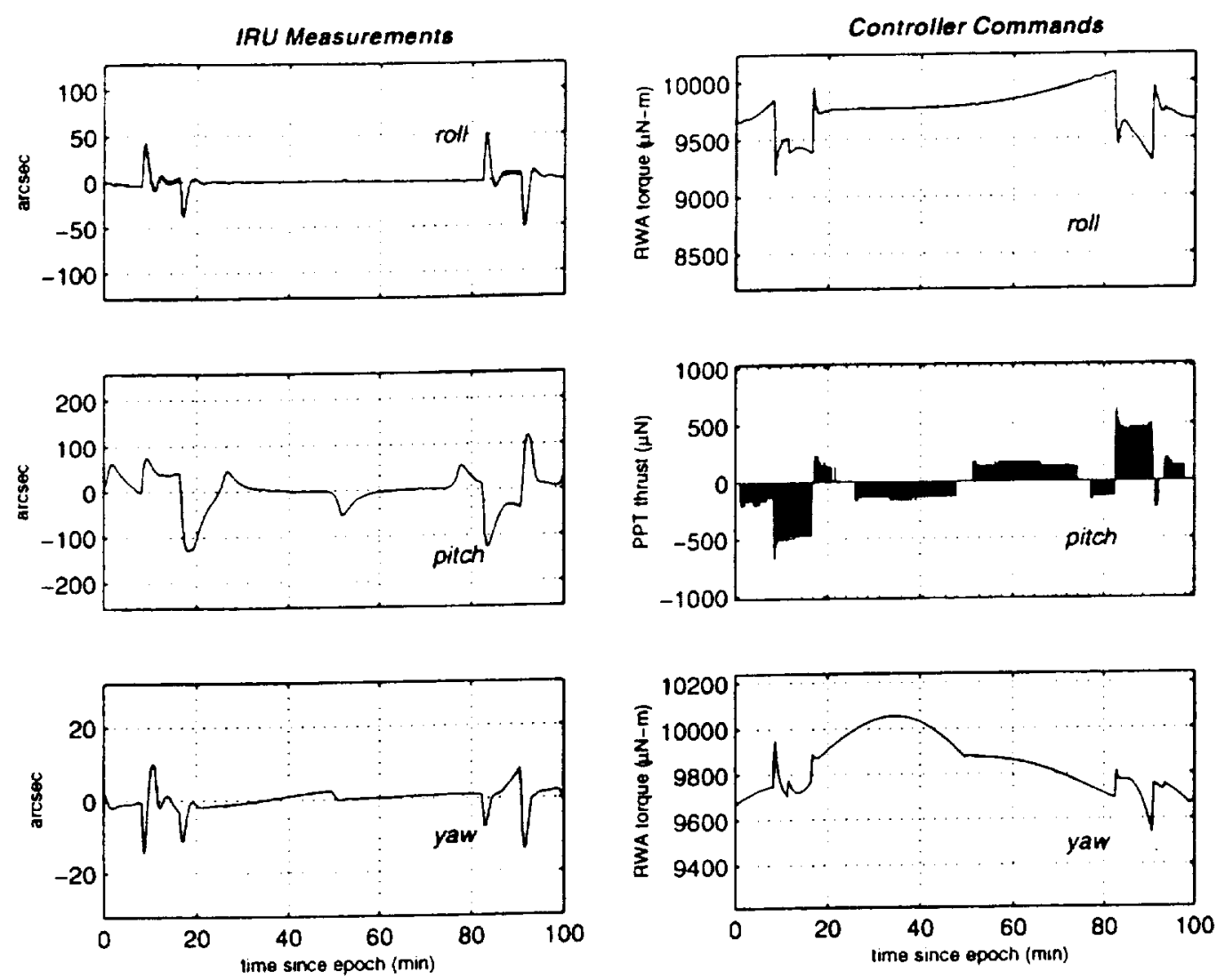

Figure 12: PPT Control Simulations Results

separating the spark plug capacitor charging circuit from the main capacitor charge circuit. Increasing the impulse bit would reduce the settling time for slew maneuvers and increase slew rate capability. This could be accomplished by increasing the capacitance size of the main capacitor.

\section{Implementation on spacecraft}

In addition to the controller described above for Mission Idle Mode, the attitude control subsystem provided accommodations required to implement the PPT experiment. These accommodations included the logic and commands to transition from all wheel control to PPT control, override commands for PPT checkout, fault detection and correction software, and telemetry for experiment validation.

\section{Transition to PPT control}

A single command was created to transition the spacecraft from all reaction wheel control to PPT control. The command invokes an on-board algorithm that effects the transition in two phases. In the first phase. the pitch momentum wheel is compared to a momentum limit value set for PPT transition (nominally set at $0.07841 \mathrm{Nms}$ ). If the pitch wheel momentum is greater than the momentum limit value. the appropriate PPT is fired at its maximum capacity to provide a torque in the same direction as the reaction wheel. This torque will cause the momentum wheel to spin down and drop below the momentum limit value.

Once the pitch wheel drops below this limit value, the second phase of the transition begins. The PPT assumes control and zero torque commands are sent to the pitch wheel so it will continue to spin down until it stops. To transition back to all wheel control, a single command is used that zeros PPT commands and immediately uses all three-reaction wheels for control independent of spacecraft momentum or any other initial condition.

\section{Commands, Fault Detection, Telemetry}

An override command is used to fire the PPT when the spacecraft is under all wheel control and not in PPT control mode. This command allows the operator to select the side of the PPT to fire, the capacitor charge time, and the number of times to repeat the firing. The same command can be used to cancel issued PPT commands. The override commands will be used to verify PPT survival and to calibrate PPT torque levels prior to initiating autonomous PPT operation. 
A single PPT Failure Detection and Correction (FDC) test is used in the attitude control software. This test checks the number of consecutive times the PPT is commanded $i$ be fired at a given capacitor charge time (initially set to the maximum charge time). If this number exceeds the set limit value (initially set to 100 times) the spacecraft is immediately sent back into all wheel control. The PPT FDC test is only active when the spacecraft is using the PPT in closed-loop control. It is not active during the first phase of the transition from wheel mode to PPT mode.

The ACE relays the PPT voltage, temperature. and fuel bar status telemetry points. The main discharge capacitor and spark plug capacitor voltages most directly indicate the state of health of the PPT. The main capacitor voltage determines the capacitor energy state and the spark plug voltages indicate if discharge ignition occurs. Special arrangements are taken to ensure that the voltage telemetry is relayed in a manner that provides the most useful information within the constraints of the spacecraft. The value of the main capacitor voltage at five different time increments within the 1 second $\mathrm{ACE}$ cycle is returned to indicate the main capacitor charging profile. In addition, the $A C E$ returns the voltage of the main capacitor at the ACE $25 \mathrm{~Hz}$ cycle that occurs prior to the ACE cycle in which the fire command is issued. This voltage indicates the maximum charge level prior to discharge. The ACE also returns the main capacitor voltage during the last 40 msec ACE cycle in each 1-second control cycle. This voltage should be zero during PPT operations. Similarly, for each 1 second control cycle both spark plug voltages are returned for the ACE cycle that occurs immediately before the ACE cycle in which the spark plug fire command is issued and for the last ACE cycle within the $1 \mathrm{~Hz}$ control cycle.

In addition to the hardware specific telemetry described above, several PPT software telemetry points are available for analysis from the ACS. The most useful PPT software telemetry points for performance analysis are the cumulative charge time counters. There is a separate counter for each side of the PPT. These counters accumulate the total time the PPT is commanded to charge the main capacitor prior to firing on a particular side.

\section{On-Orbit Validation Plans}

The ultimate objective of the EO-1 PPT flight experiment is to collect science images while the spacecraft is using the PPT in closed-loop control. Comparing these images to similar ones taken under all wheel control will provide a means of evaluating PPT performance and impact. if any, on the spacecraft and its instruments. This objective will be approached by a sequence of steps that build confidence in the PPT and its implementation. After each step. PPT and spacecraft performance will be evaluated. Software control parameters will be adjusted and steps repeated as needed. The general steps are outlined in Table 5.

Table 5: PPT Validation Plan

\begin{tabular}{|l|l|}
\hline Step & Description \\
\hline 1 & Calibrate PPT using override commands \\
\hline 2 & $\begin{array}{l}\text { Switch to PPT during communication ground pass } \\
\text { in Mission Idle Mode }\end{array}$ \\
\hline 3 & $\begin{array}{l}\text { Operate in PPT control in Mission Idle Mode for } \\
\text { one orbit or greater }\end{array}$ \\
\hline 5 & $\begin{array}{l}\text { Operate in PPT control in Mission Idle Mode for at } \\
\text { least one science image data collection event }\end{array}$ \\
\hline 5 & $\begin{array}{l}\text { Operate in PPT control in Mission ldle Mode for an } \\
\text { extended number of orbits and multiple science } \\
\text { image data collection events }\end{array}$ \\
\hline
\end{tabular}

\section{Conclusion}

The EO-1 Pulsed Plasma Thruster experiment has been designed to validate the capability of a new generation of PPTs to perform spacecraft attitude control functions. A minimum number of changes were required of the attitude control subsystem to incorporate the PPT flight hardware design. Simulations of the PPT operation estimated the worst-case roll, pitch, and yaw errors to be 52,129 , and 14 arcsec, respectively.

\section{References}

1. Meckel. N.J., Cassady, R.J.. Osborne. R.D. Hoskins. W.A., and Myers. R.M.. "Investigation of Pulsed Plasma Thrusters for Spacecraft Attitude Control. " IEPC-97-128. Au. 1997.

2. Cassady, R.J.. Morris, J.P., Vaughan. C.E.. Willey, M.J., "New Attitude Control Strategies Using Pulsed Plasma Thruster Systems," AAS 98-065. February, 1998

3. M.J.Cully, C. Gay, J. Thurber. "Small Spacecraft Bus Development in the New Millennium" 12th AlAA / USU Conference onSmall Satellites. September 1998

4. Benson. S.W.. Arrington. L.A., Hoskins. W.A. "Development of a PPT for the EO-I Spacecraft". AIAA-99-2276. June 1999.

5. Arrington, L.A.. Haag. T.W.. "Multi-Axis Thrust Measurements of the EO-1 Pulsed Plasma Thruster". AlAA 99-2290. June 1999.

6. Hoskins. W.A. Witson. M.J.. Willey, M.J.. Meckel, N.J.. Camphell. M. Chung. S.. "PPT Development Efforts at Primex Aerospace Company". AlAA 99. 2291, Junc 1999.

7. Sidi.Marcel J.. Spaceraft Dimamics and control. Cambridge liniversity Press. Neu York, 1997 